\title{
A Study on Evaluation of Non-Market Value of Islands with Fewer Than 10 Residents in Korea Using CVM
}

\author{
Park, Sung-Hyun \\ Institution for Marine and Island Cultures, Mokpo National \\ University, Mokpo, Republic of Korea
}

\section{Lee, Gyeong-A (corresponding author) \\ Institution for Marine and Island Cultures, Mokpo National University, Mokpo, Republic of Korea \\ lga3285@naver.com}

\author{
Choi, Jung-Hun \\ Department of Economics, Mokpo National University, Muan- \\ gun, Republic of Korea
}

Publication Information:

Received 21 November 2019, Accepted 1 December 2019, Available online 16 December 2019

DOI: 10.21463/jmic.2019.08.2.08

\begin{abstract}
While the importance of islands has recently emphasized in regards to the upholding of marine sovereignty, there is no research which evaluates the proper value of islands. Thus, this study was conducted to evaluate the non-market values of islands, as well as the estimated interest by the public in Korean islands with fewer than 10 residents, using CVM. To estimate the non-market value, a survey was conducted on 500 respondents randomly selected from the Korean population. They were asked to tell how much they would pay to buy an island. The median value of the responses was 2,011. It was evaluated to be 40.182 billion Won. $74 \%$ of respondents said they would pay the offered price, and, among the reasons for willing to pay the price, $41.9 \%$ or the largest proportion of respondents, noted that 'even if it is unclear how to make use of the island in the future, it needs to be preserved'. The findings of this study which quantified the values of islands with fewer than 10 residents, can be used as objective data to secure the project to prevent those islands from being uninhabited. The findings of this study will be useful quantitative information for decision-making on policies regarding islands with fewer than 10 residents. In particular, this study expects that, by suggesting public interest in these islands, the findings of this study can be used to strengthen national awareness on the importance of islands with fewer than 10 residents.
\end{abstract}

\section{Keywords}

Small Islands with Fewer than 10 Residents, Non-market value, Contingent valuation method, Public Value 


\section{Introduction}

To publicize the importance and value of islands, the Korean government recently designated 'Island Day' (August 8). With such efforts, people are increasingly interested in islands. However, islands located on the peripheries of the mainland have suffered from its population draining to urban areas, because of poor living conditions and economic structures of them, leading to polarization of the national territories.

While Korean islands plays very important roles in the respect of national security and protection of marine sovereignty, they were under a disarray of island policies and management, and were thus unable to prevent escape of people to cities. It is expected that within the next 50 years, over 70 islands will become uninhabited (Korea Research Institute for Local Administration, 2017). In particular, islands on territorial waters and islands with fewer than 10 residents will see the decrease in its residential population accelerate further with the share of the elderly taking up an increasingly large share of the islands' population.

Up to now, the Korean government, to prevent islands from being vacant, established the Island Development Promotion Act, which designated 371 islands as the islands for development, and categorized them into special situation areas (186 islands) and growth promotion areas (185 islands). But, unfortunately, islands with fewer than 10 residents are not included in either of the two categories. Thus, they are at the blind spot of the policy.

After the UN Convention on the Law of the Sea (UNCLOS) was established in 1982, islands have become more important than before due to territorial disputes among countries over islands, and there has been active discussion on the values of islands. But, there have been few researches on economic values of islands. That is, the value of islands has not been evaluated on a full scale. There have been some researches on ecology of islands and resource values of them, but, there have been few researches on the economic values of them. A study on the economic value of Dokdo is almost the only study in this respect (Yu et al, 2011; Lee, 2013). Applying the MAUT/CVM model, Yu et al(2011) estimated nonmarket value of Dokdo, calculating its values as 1 trillion Won and 172.4 billion Won, respectively. According to Lee, C.G(2013), the preservation value of Dokdo is 80,638 Won per household, and estimated its total value as 1 trillion and 398.2 billion Won. Besides, Gwak, et al (2002a, 2002b) estimated preservation values of the Hanryeo Marine National Park, and the Woopo Swamp, applying the conditional value estimation method, and Choi(2004) estimated the economic value of mud flat, using the PSIR technique.

The value of an island consists of market value based on its marine biology, mineral resources, and visitors, and nonmarket value from its historical and symbolic value and value as marine territory. Up to now, in the value calculation of an island, unused value of environment has been ignored, but the total value of environment should be added to used and unused value of the island. In this respect, in the evaluation of the value of islands with fewer than 10 residents, evaluation on non-usage value of those islands should be done along with market value of them.

For example, the reason why we pay attention to the problem of calculating the economic value of the ecological system resides first in the fact that, by evaluating the value we can get from preserving natural resources, we can compare the value of use on the same scale for a single object. Second, it resides in the fact that we can make a momentum to publicize the value and importance of natural resources and ecological system which are outside of the attention of the general public (Shin, 2006: 20). Accordingly, if we can properly evaluate the value of islands with fewer than 10 residents, 
we can suggest the necessity of making policies on such islands and supporting them with budgets. The findings will also be used as basic data to raise national awareness on the importance of such small islands.

\section{Value estimation method using CVM}

Environmental value can be roughly divided into usage value and non-usage value. In the sense that usage value means economic value generated from it becoming the object of direct and indirect use of human beings, it can be divided into direct usage value and indirect usage value. In contrast, non-usage value can be classified into option value, existence value, and bequest value(Ministry of Environment 2001: 8 9). Option value is the value when one leaves the option that others can use it, even if one does not use it. Existence value is the value people can feel by the fact that it exists, even if there is no possibility that people can use it. Bequest value is the value people have by maintaining and preserving nature for future generations.

Therefore, in the case of value of natural resources or environment, it is possible to calculate the value only when we find out how much it brings utility to all the individuals(Shin, 2006: 17). In the sense that the islands with fewer than 10 residents are environment belonging to natural resources, the value of them is non-usage value, which cannot be figured out by market value. As such, in order to calculate the value, this research uses the contingent valuation method (CVM), a representative method to induce the value of a certain public goods or environmental goods. In particular, environmental goods carries value in which its existence itself can provide benefits to a third person. One of the most common methods to measure this value is the CVM (Lee, 2013).

Accordingly, to estimate economic values of islands with fewer than 10 residents, this study uses CVM, and estimates Willingness To Pay (WTP), and draws economic values citizens endow with. CVM suggests a virtual market where environmental goods can be traded, and asks people to inspect how much they would pay to buy a good. It is very useful to measure the value of non-market goods like environmental good. By making respondents decide how much they will pay to buy an island with fewer than 10 people, the findings can be used as supporting data when establishing island policies such as management and preservation of such islands.

In general, non-market value of an island can be divided into 4 kinds: historical and symbolic value, military and security value, marine territorial value, and eco-environmental and geological and topographic value (Yu et al, 2011). Considering such characteristics, this study sought to identify the non-market value of those islands. This study asked respondents how much they would additionally pay on their income tax to support the project of preventing the islands from becoming uninhabited. Here, if they are asked how much they would pay to support the project of managing the islands with fewer than 10 residents, they are likely to inflate or deflate the amount they would pay for it. So, this study asked them how much they would pay as part of increased income tax. Dichotomous choice method allows respondents to answer easily, reducing the proportion of non-response, and, as it offers several price choices at the beginning, it can reduce starting point bias (Lee, 2013). 


\section{Research Design}

This study used double-bounded questions in the dichotomous choice (DC) question method widely used in existing CVM research to measure the value of managing and preserving islands with fewer than 10 residents. In the DC method, as respondents have only to respond with a 'yes' or 'no' in a virtual market, it is easy to answer. And, as it is similar to the decision-making in market transactions, the method has merits such as strategic bias being minimized, and no starting pint bias (Hanemann 1984; Freeman 1993; Lee, 2013).

The survey on the estimated value of islands with fewer than 10 residents was conducted from mid-February to midMarch 2019. Respondents were selected from all the 16 metropolitan cities and provinces. As islands with fewer than 10 residents are scattered across Korea, respondents were chosen from across the nation. To reduce bias, samples were allocated after adjusting them with square root ratios per region and per age group. The sample size was 30 respondents for preliminary test, and 500 for real survey. The sampling design per region was based on the statistics on the number of population per region in the 2019 census. Respondents were Korean adults of 20 years old or above. To conduct a CVM survey, a structured questionnaire was used. The survey was carried out via telephone.

Table 1. Samples

\begin{tabular}{|c|c|c|c|c|c|c|}
\hline Area & 20's & 30 's & 40's & 50 's & 60 's or older & Total \\
\hline Gangwon·Jeju area (Gangwon, Jeju) & 10 & 10 & 10 & 10 & 15 & $55(11 \%)$ \\
\hline Metropolitan area (Seoul, Gyeonggi, Incheon) & 30 & 35 & 35 & 35 & 40 & $175(35 \%)$ \\
\hline Youngnam area (Gyeongnam, Gyeongbuk, Daegu, Busan, Ulsan) & 20 & 20 & 25 & 25 & 30 & $120(24 \%)$ \\
\hline Chungcheong area (Chungnam, Chungbuk, Daejeon) & 15 & 15 & 15 & 15 & 20 & $80(16 \%)$ \\
\hline Honam area (Jeonnam, Jeonbuk, Gwangju) & 10 & 10 & 15 & 15 & 20 & 70 (14\%) \\
\hline Total & $85(17 \%)$ & $90(18 \%)$ & $100(20 \%)$ & $100(20 \%)$ & $125(25 \%)$ & $500(100 \%)$ \\
\hline
\end{tabular}

The questionnaire first suggested the basic current situation of islands with fewer than 10 residents, settlement safety of them, and the need to support them systematically, and, as a way to financially support such a project, the method of adding extra tax on the current income tax. Then, it asked them how much they would pay in addition to the existing income tax. Respondents were given detailed explanation on the virtual scenario called the project to support the management and preservation of islands with fewer than 10 residents. Then, they were offered certain amounts of money they would bear to support the project. Using DC method, they were asked to answer 'yes' or 'no' on the amount of money (Yu et al, 2011; Lee, 2013).

Double-bounded choice-type question asks a respondent whether he or she was willing to pay the suggested amount, and, if the respondent says 'yes', asks the respondent whether he or she was willing to pay the amount equivalent to two times the original amount. And, if the respondent gave a 'no', the question then asked whether he or she was willing to pay the amount equivalent to half of the original amount. 
Before starting the real survey, this study commissioned the pretest of the real survey where 50 respondents were randomly selected, and they were allocated properly on the criteria of gender, age, and income. In the test, the range of amounts which would be offered to respondents in the real survey was determined, excluding extreme outliers. The suggested amounts are four options, ranging from 500 Won to 4,000 Won as the maximum. Each of the four options was randomly allocated to respondents. The number of copies of the questionnaire containing each option was 125 , and 4 options were allocated equally among 500 copies of the questionnaire. The characteristics of respondents are shown in Table 2.

Table 2. Respondent characteristics

\begin{tabular}{|c|c|c|c|}
\hline \multicolumn{2}{|r|}{ Categorization } & \multirow[t]{2}{*}{ Frequency } & \multirow[t]{2}{*}{ Percent (\%) } \\
\hline Gender & Male & & \\
\hline & Female & 244 & 48.8 \\
\hline \multirow[t]{5}{*}{ Age } & 20 's & 85 & 17.0 \\
\hline & 30 's & 90 & 18.0 \\
\hline & 40 's & 100 & 20.0 \\
\hline & 50 's & 100 & 20.0 \\
\hline & More than 60 's & 125 & 25.0 \\
\hline \multirow[t]{5}{*}{ Area } & Gangwon·Jeju area & 55 & 11.0 \\
\hline & Metropolitan area & 175 & 35.0 \\
\hline & Youngnam area & 120 & 24.0 \\
\hline & Chungcheong area & 80 & 16.0 \\
\hline & Honam area & 70 & 14.0 \\
\hline \multicolumn{2}{|l|}{ Total } & 500 & 100.0 \\
\hline
\end{tabular}

As the analytic model to draw the WTP representative value, this study used utility difference model. If the question offers $A$, and asks respondent whether he or she is willing to pay that amount, the respondent will answer 'yes' if his or her WTP is larger than A, And, if his or her WTP is smaller than $A$, the respondent will answer 'no'. By answering like these, the respondent can maximize the utility of himself or herself. Utility gap is expressed as $\Delta v$. The CVM estimation model is as follows.

\section{(1) Indicator function}

When we assume that $i(=1,2,,, N)$ is each respondent of the sample, and that the initially offered amount is $A_{i}$, and the secondly offered higher amount and lower amount are $A_{i}^{H}, A_{i}^{L}$ respectively, indicator functions can be expressed as follows.

$$
\begin{aligned}
& I_{i}^{Y Y}=1 \text { (If the } i t h \text { respondent answers "yes-yes") } \\
& I_{i}^{Y N}=1 \text { (If the } i t h \text { respondent answers "yes-no") } \\
& I_{i}^{N Y}=1 \text { (If the } i t h \text { respondent answers "no-yes") }
\end{aligned}
$$




$$
I_{i}^{N N}=1 \text { (If the } i t h \text { respondent answers "no-no") }
$$

(2) Construction of log-likelihood function of dichotomous choice model on $\mathrm{N}$ respondents.

$$
\begin{aligned}
\operatorname{InL}= & \sum_{i=1}^{N}\left\{I_{i}^{Y Y} \operatorname{In}\left[1-G_{c}\left(A_{i}^{H}\right)\right]+I_{i}^{Y N} \operatorname{In}\left[G_{c}\left(A_{i}^{H}\right)-G_{c}\left(A_{i}\right)\right]\right. \\
& \left.+I_{i}^{N Y} \operatorname{In}\left[G_{c}\left(A_{i}\right)-G_{c}\left(A_{i}^{L}\right)\right]+I_{i}^{N N} \operatorname{In} G_{c}\left(A_{i}^{L}\right)\right\}
\end{aligned}
$$

(3) Cumulative distribution function of WTP

$$
G_{c}(A)=[1+\exp (a-b A)]^{-1}
$$

\section{Analysis}

A review of the estimated non-market value of islands with fewer than 10 residents using CVM showed that, among the

\begin{tabular}{|c|c|c|c|c|c|c|}
\hline & & \multicolumn{5}{|c|}{ Response } \\
\hline & & $Y-Y$ & $\mathrm{Y}-\mathrm{N}$ & $\mathrm{N}-\mathrm{Y}$ & $\mathrm{N}-\mathrm{N}$ & Total \\
\hline \multirow{5}{*}{ Offered amount } & 500 Won & 70 & 12 & 5 & 38 & 125 \\
\hline & 1,000 Won & 49 & 20 & 19 & 37 & 125 \\
\hline & 2,000 Won & 41 & 27 & 19 & 38 & 125 \\
\hline & 4,000 Won & 41 & 26 & 19 & 39 & 125 \\
\hline & Total & $201(40.2 \%)$ & $85(17.0 \%)$ & $62(12.4 \%)$ & $152(30.4 \%)$ & $500(100.0 \%)$ \\
\hline
\end{tabular}
responses on four kinds of offered amounts, the proportion of $\mathrm{Y}-\mathrm{Y}$ was the largest (40.2\%), and that of N-N was the second largest (30.4\%).

Table 3. The estimation of non-market value of islands with fewer than 10 residents using CVM revealed

First, among 201 respondents who answered $Y-Y$, the mean of the highest WTP was 9,090 Won. In addition, among 152 respondents who answered N-N, 22 were willing to pay, and the mean of the WTP for them was 302 Won. To 370 respondents who are willing to pay, this study asked the reason why they wanted to pay, and the findings are as follows: 'Even if it is not clear how the islands can be used in the future, they needs to be preserved' (41.9\%); 'The islands have natural, environmental values'(24.9\%); 'We need to establish marine sovereignty' (22.2\%) in descending order.

Next, among N-N respondents, 130 (26\%) were not willing to pay any amount. The reasons for not paying for them were as follows: 'It should be resolved with the tax I already paid' (30.0\%); 'This issue is not important enough to be treated as a priority' (23.1\%); 'I cannot afford to pay more' (13.1\%); 'I do not have trust in the project as suggested by the government' (8.5\%).

The estimation results using Logit model based on the above statistics are shown in Table 4. 
Table 4. The estimation results using Logit model

\begin{tabular}{|l|l|l|l|}
\hline \multicolumn{1}{|c|}{ Variable } & \multicolumn{1}{c|}{ Coefficient } & \multicolumn{1}{c|}{ t } & \multicolumn{1}{c|}{$\mathrm{p}$-value } \\
\hline $\begin{array}{l}\text { Constant } \\
\text { In(bid) }\end{array}$ & 5.7557 & 15.144 & $0.000^{\star \star \star}$ \\
\hline $\mathrm{N}$ & -0.7567 & -14.720 & $0.000^{\star \star \star}$ \\
Log-likelihood & 500 & & \\
\hline
\end{tabular}

Footnote: ${ }^{\star \star \star}$ means significance at significance level $1 \%$.

Here, variable is constant number, $\ln ($ bid) is log value for offered amount. In coefficient, the sign of $\ln ($ bid) is negative (-), which means that the higher the offered amount gets, the smaller utility of respondent gets, and the probability of answering 'yes' decreases. And, p-value indicates significance level, and estimation results were analyzed to be significant at $1 \%$ level.

There are two kinds of estimating WTP. As shown in Figure 1, the median of WTP is the value when the probability of answering 'yes' becomes 0.5 . In this analysis, the value is 2,011 Won. The mean of WTP is the area below the curve, and it calculates the area up to the maximum offered amount. In this analysis, it is 3,410 won. In summary, the estimation of WTP on income tax to manage and support islands with fewer than 10 residents showed that its median is 2,011 Won, and the mean is 3,410 Won.

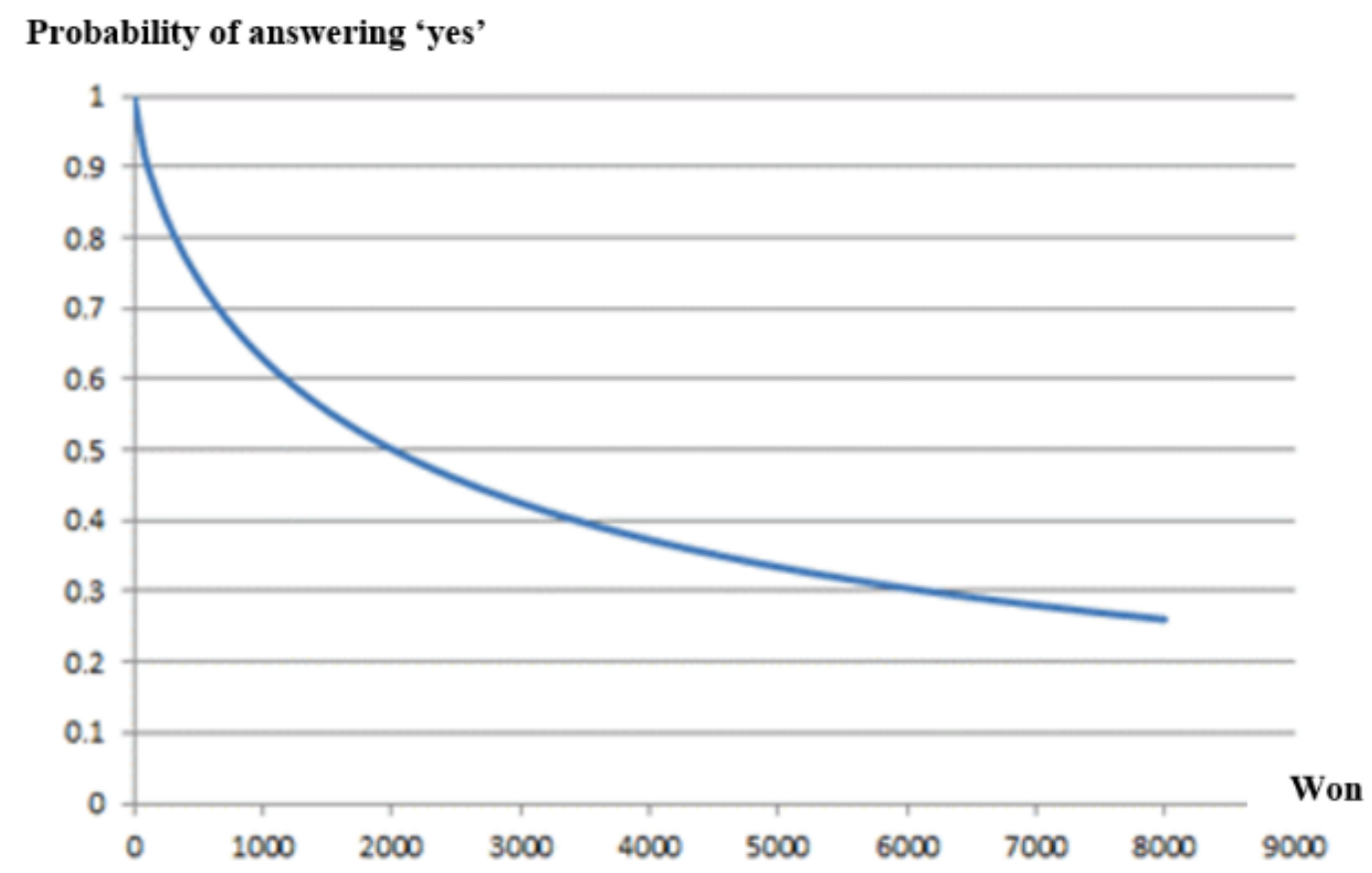

Fig 1. Graph based on Logit model estimation 
One of the important purposes of performing CVM research is to estimate biases of the whole population using the information acquired from sample. Accordingly, a purpose of this research is to estimate the characteristics of the Korean people using the information acquired from the sample of 500 respondents in five regions of 16 local governments. We can use the median and mean values of WTP to estimate how willing Koreans are to pay additional tax to support islands with fewer than 10 residents. As of 2019, the number of total households in Korea is 19,971,359 (Statistics Korea, 2019). If we multiply the median and mean values with the number of households, WTP of Korean people becomes 40.162 billion Won a year, when we apply the median, and 68.102 billion Won when we apply the mean. Theoretically, using the mean value is more desirable, as the median value is known to be less reliable.

\begin{tabular}{|l|l|l|}
\hline \multicolumn{1}{|c|}{ Logit Model } & \multicolumn{1}{|c|}{ WTP(Won/household/year) } & \multicolumn{1}{c|}{ Total value(Won/year) } \\
\hline Median value & 2,011 & $40,162,402,949$ \\
\hline Mean value & 3,410 & $68,102,334,190$ \\
\hline
\end{tabular}

\section{Conclusion}

If the value of nature is expressed in monetary value, it can be easily delivered in the decision-making process. This has the merit of allowing us to assign priority to various factors in decisions made concerning environmental policy. Even of efforts to evaluate values on non-market goods and services provided by a given environment have been made continuously, the value of islands has not been the target of research, even if it is very important.

It is well-known that islands with fewer than 10 residents have been located at the blind spot of island policies the government has pursued. Though islands have been treated in the perspective of humanities and ecology such as their histories, folklores, and tourism, etc., there have been few researches on economic values of islands.

Thus, this study tried to evaluate non-market values of islands with fewer than 10 residents with the survey asking respondents how much they would pay to manage and preserve them, using CVM. It is the way to estimate public interest values to manage and preserve those islands. Up to now, CVM has been applied to evaluate preservation values of Woopo Swamp and its surrounding wetland, values of eco-tourism of DMZ, non-market value of Dokdo, and economic values of Hanryeo Marine Park and mud flat, etc.

The analysis found that the non-market value of islands with fewer than 10 residents was 40,162 billion Won when we apply the median. Using the sample drawn from the Korean population, this study, in dichotomous choice questions, asked respondents how much they would pay to support managing and preserving those islands. The median value of WTP among respondents was 2,011 Won. If we multiply this value with the number of household in Korea, the total WTP of Korean people becomes 40.162 billion Won. Among the 500 respondents, 370 (74\%) were willing to pay additional tax to the project to manage and preserve such islands. The reasons why they would pay are as follows: 'Even if it is not clear how the islands can be used in the future, they needs to be preserved' (41.9\%); 'The islands have a natural, environmental value' (24.9\%); 'We need to establish marine sovereignty' (22.2\%). We can identify that management and 
preservation of those islands are perceived by the Korean people as very important, even though many of them have never set foot on these islands.

The implications of the findings of the survey on non-market value of islands with fewer than 10 residents are as follows. First, though the non-market value of those islands was evaluated as lower than the economic value of Dokdo, among the responses to four kinds of answering types, the proportion of $Y-Y$ (yes-yes) was the highest $(40.2 \%)$, and the proportion of respondents who expressed the willingness to pay additional tax reached as high as $74 \%$. So, the government need to consider such a characteristics of public opinion on those islands when it establishes policies to support those islands.

Second, this study expects that the findings of this study quantifying non-market value of islands with fewer than 10 residents can be used as basic sources for the followings: (1) evaluation of economic validity of the project to support those islands; (2) decision of the direction on how to manage and preserve those islands; (3) establishment of a systematic and comprehensive policies on those islands; (4) establishment of policies to change perception of the people regarding the management and preservation of those islands. Through research and studies on evaluation of non-market value of islands with fewer than 10 residents, we need to publicize the value and importance of those islands to the people. Moreover, we need to continue to pay attention to and support those people residing in those islands who have the rights to pursue happiness as humans.

The present study overlooked the possibility of different prices depending on the level of understanding of the islands. A follow-up study will further look at this topic.

\section{References}

Kim, Chung-sil, Lee, Sang-ho, 2002, Estimate the conservation value of wethands using the CVM method, Rural Economy, 25(4), pp.31-44. (Korean with English abstract).

Kwak, Seung-jun, Yoo Seung-hoon, Cho, Seung-kuk, 2002, The Economic Value of Preserving Hallyue Marine National Park - A Case Study of CVM, The Korean Journal of Economic Studies, 50(2), pp.85 104. (Korean with English abstract).

Kwak, Seung-jun, Yoo Seung-hoon, Lee, Chung-ki, 2002, Using the Contingent Valuation Method to Measure the Conservation Value of the Woopo Wetland, International Economic Journal, 8(3), pp.203 225. (Korean with English abstract).

Shin, Chul-ho, 2006, An Introduction to the Economic Valuation: a Basic Concept and the Theories, Monthly Marine Fisheries, 258 , pp.16 25. (Korean)

Yoo, Seung-hoon, Lee, Joo-suk, Chung, Young-keun, 2011, Assessment of Non-market Value of Dokdo, Ocean and Polar Research, 33(3), pp.223 233. (Korean with English abstract).

Lee, Dong-kun, Youn, So-won, 1999, A Study on the Economic Evaluation of Conservation Value of Coast Wetland-A case study of Kang-Hwa island, The Industrial Science Researches 7, pp.141-154. (Korean with English abstract).

Lee, Choong-ki, 2005, Valuation of Eco-tourism Resources for DMZ using a Contingent Valuation Method: International Comparison of Values, Journal of Tourism and Leisure Research, 17(4), pp.65-81. (Korean with English abstract). 
Lee, Choong-ki, 2013, Estimating the Preservation Value of Dokdo: Using Two Stage Contingent Valuation Method, Journal of Tourism Sciences, 37(4), pp.117 139. (Korean with English abstract).

Choi, Mi-hee, 2004, Economic value of the Koeran mudflat wetland, Journal of Korean Wetlands Society, 6(1), pp.89 104. (Korean with English abstract).

Freeman III, A. M., 1993, The Measurement of Environmental and Resource Value, Resources for the Future, Washington, D. C.

Hanemann, W. Michael, 1984, 「Welfare Evaluations in Contingent Valuation Experiments with Discrete Response」, American Journal of Agricultural Economics, 66, pp. 332-341.

Lee et al, 2016, A Study on the Development Plan and Analysis of the population change of the island, Korea Research Institute Institute for Local Administration. (Korean)

Dixon, J . and Hufschmidt, M. (1986), Economic Valuation Techniques for the Environment, The Johns Hopkins University Press.

Garrod, G. and Willis, K. G. (1999), Economic Valuation of the Environment, Edward Elgar, Cheltenham·Northampton.

Ministry of Environment, 2001, A Study on Measuring the Economic Value of Natural Assets, (Korean) 